\title{
Hyperhomocysteinemia and the role of B vitamins in cancer
}

\author{
Nadja Plazar and Mihaela Jurdana \\ College of Health Care Izola, University of Primorska, Izola, Slovenia \\ Received 28 October 2009 \\ Accepted 16 March 2010 \\ Correspondence to: Nadja Plazar, PhD, University of Primorska, College of Health Care Izola, Polje 42, 6310 Izola, Slovenia. \\ Phone: +386 566264 60; Fax: +386 566264 80; E-mail: nadja.plazar@vszi.upr.si \\ Disclosure: No potential conflicts of interest were disclosed.
}

Background. Patients suffering from malignancies have increased complications due to corresponding cardiovascular diseases and risk factor for the development of venous thromboembolism. Epidemiological studies have shown that increased homocysteine plasma concentration (hyperhomocysteinemia) is related to a higher risk of coronary heart disease, stroke, peripheral vascular disease and malignancies. Homocysteine (tHcy) is an intermediate sulfurcontaining amino acid produced from methionine during processing of dietary proteins. The plasma homocysteine levels are strongly influenced by diet, as well as by genetic factors. Folic acid, vitamins B6 and B 12 are dietary components which influence the plasma homocysteine levels the most. Several studies have found that high blood levels of $B$ vitamins are related to the integrity and function of DNA, and, are at least related to lower concentration of homocysteine. Folate depletion has been found to change DNA methylation and DNA synthesis in both animal and human studies. Because of this critical role of folate, most studies including homocysteine have focused on these two actions. Conclusions. Hyperhomocysteinemia proves to be the most common condition highly associated with both venous and arterial thrombosis in many cancer patients, while the associated pathophysiology has not been precisely established yet. Therefore, of current interest is the possible role of folate metabolism developing into a cancer initiating hyperhomocysteinemia. This review will discuss this possibility.

Key words: homocysteine; hyperhomocysteinemia; B vitamins; cancer

\section{Introduction}

It has been long postulated that the plasma homocysteine concentration is inversely related to the occurrence of cardiovascular and cerebrovascular diseases. ${ }^{1}$ More recently, increased plasma homocysteine concentration has been postulated as a risk factor for cancer and even as a novel tumour marker. ${ }^{2}$ This increased risk can be attributed to the high prevalence of classical factors in these patients, such as hypertension, diabetes, and dyslipidemia, but most certainly (also) to factors resulting from the malignant disease and the applied selected therapy. For example, back in 1865 Trousseau described hypercoagulability and increasing risk of »spontaneous coagulation « in patients with cancer. ${ }^{3}$ Nowadays, it is established that breast, pancreas, and gastrointestinal cancers are associated with a higher incidence of thrombo- sis. With more advanced stages of cancer there is a lower overall survival rate, ${ }^{4}$ but, also a greater risk of venous thromboembolism ${ }^{5}$, what can additionally influences on the survival of patients. A raised plasma homocysteine level is associated with serum B vitamins concentration, especially folate levels, since these are required in homocysteine metabolism. Adequate B vitamins intake is essential for nucleotide biosynthesis, DNA replication and methyl group supply and thus for cell growth and repair. ${ }^{6}$ Evidence suggests that folate depletion fosters the development of cancer, particularly colorectal cance ${ }^{6-10}$, whereas high doses of folic acid may enhance growth of cancer cells. ${ }^{7}$ However, the complexity of the folate metabolic pathway may suggest that different metabolites of folate might induce multiple effects in normal, preneoplastic and malignant cells. 


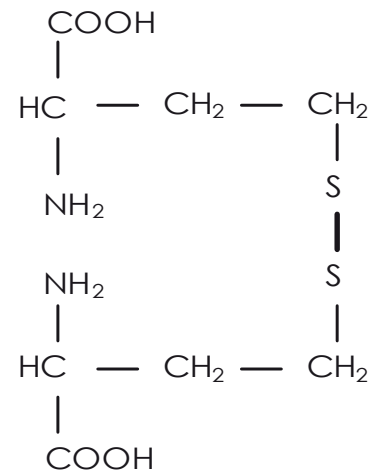

homocystine

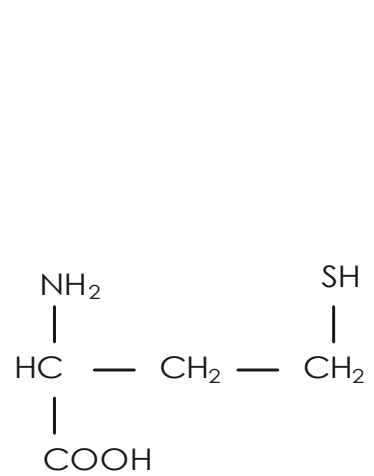

homocysteine

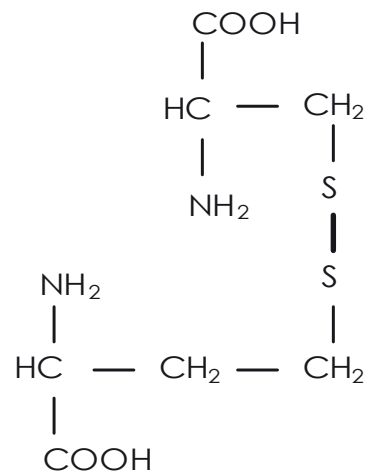

cysteine-homocysteine

FIGURE 1. Structural formulae: Homocysteine, homocystine and mixed disulfide (cysteine-homocysteine).

\section{Homocysteine, metabolism and cardiovascular complications}

Proliferating cells secrete more homocysteine compared to non-proliferating cells. Homecysteine is a sulphur-containing intermediate in the normal metabolism of the essential amino acid methionine present in almost all body cells and mostly 5 to $10 \%$ of daily synthesized homocysteine $(1.2 \mathrm{mmol} /$ day $)^{11}$ is transferred into the blood through hepatocytes. The thyol group of homocysteine makes it readily available to be oxidized in the blood at physiological $\mathrm{pH}$ upon which it forms disulfide bonds with other thyols (Figure 1). ${ }^{12}$

In a healthy population the frequency of moderate hyperhomocysteinemia $(12-30 \mu \mathrm{mol} / \mathrm{L})$ is 5 to $7 \%$, with higher values for men being attributed to gender differences like estrogen presence in women. This is confirmed by the fact that after menopause the blood levels of homocysteine of woman approximate those in men. ${ }^{13}$ Another cause for moderate hyperhomocysteinemia is an unbalanced diet with suboptimal intake of vitamins (B6, B12 and folates), acting as coenzymes in the metabolism of homocysteine. ${ }^{14,15}$ In the elderly, such a moderate hyperhomocysteinemia due to lack of vitamins B and folates is very common. A survey, carried out by Herrmann et al., showed that $32 \%$ of healthy elderly people aged 65 to 75 , and $58 \%$ of those over 85 years of age suffer from hyperhomocysteinemia, indicating that hyperhomocysteinemia significantly increases with age ${ }^{16}$, therefore it decreases in younger people as the incidence of malignancies. ${ }^{17}$

Via the trans-sulfuration pathway homocysteine is converted into cystathionine to form cysteine by cystathionine-ß3-synthase, with vitamin B6 as a co-factor. Another pathway of homocysteine metabolism is the re-methylation pathway, which is connected with the folate metabolic pathway. It involves the transfer of a methyl group from 5-methyl-tetrahydrofolate to homocysteine to form methionine, and eventually S-adenosylmethionine. The methyl transfer from 5-methyl-tetrahydrofolate to homocysteine is catalyzed by methionine-synthase, and requires vitamin $\mathrm{B} 12$ as a cofactor (Figure 2). Important to notice is that S-adenosylmethionine is the universal methyl donor for methylation reactions. The resulting tetrahydrofolate transfers into the 5.10 methyltetrahydrofolate with the enzyme 5.10 methyltetrahydrofolate reductase (MTHFR) and then into the 5 methyltetrahydrofolate (5-MTHF). ${ }^{18}$ Cellular availability of 5-MTHF may be of great importance in regulating cellular effects of homocysteine related to cell growth. Therefore, deficiencies of folate and vitamin B12 and reduced activity of the involved metabolic enzymes will inhibit the breakdown of homocysteine, which will lead to an increase of the intracellular homocysteine concentration. ${ }^{19}$

Moreover, hereditary causes of increased homocysteine blood concentrations exist (hyperhomocysteinemia). Most studies refer to changes in the genes for those enzymes that lead to severe hyperhomocysteinemia, such as the CBS gene (cistation- $\beta$ syntases) or in the GCT gene ( $\gamma$ cistationase), both coding the trans-sulfuration pathway. Further, mutations do occur in genes coding for enzymes involved in the remethylation pathway and the related folate metabolic pathway. For a homozygous person with a mutation MTHFR $677 \mathrm{C} \Rightarrow>\mathrm{T}$ the enzyme activity is reduced to $35 \%$ of the normal. ${ }^{20} \mathrm{~A}$ typical mutation in Europe occurs within the gene for MTHFR $677 \mathrm{C}=>\mathrm{T}$, with different incidences between German (24.5\%) and Italian (43.8\%) popula- 


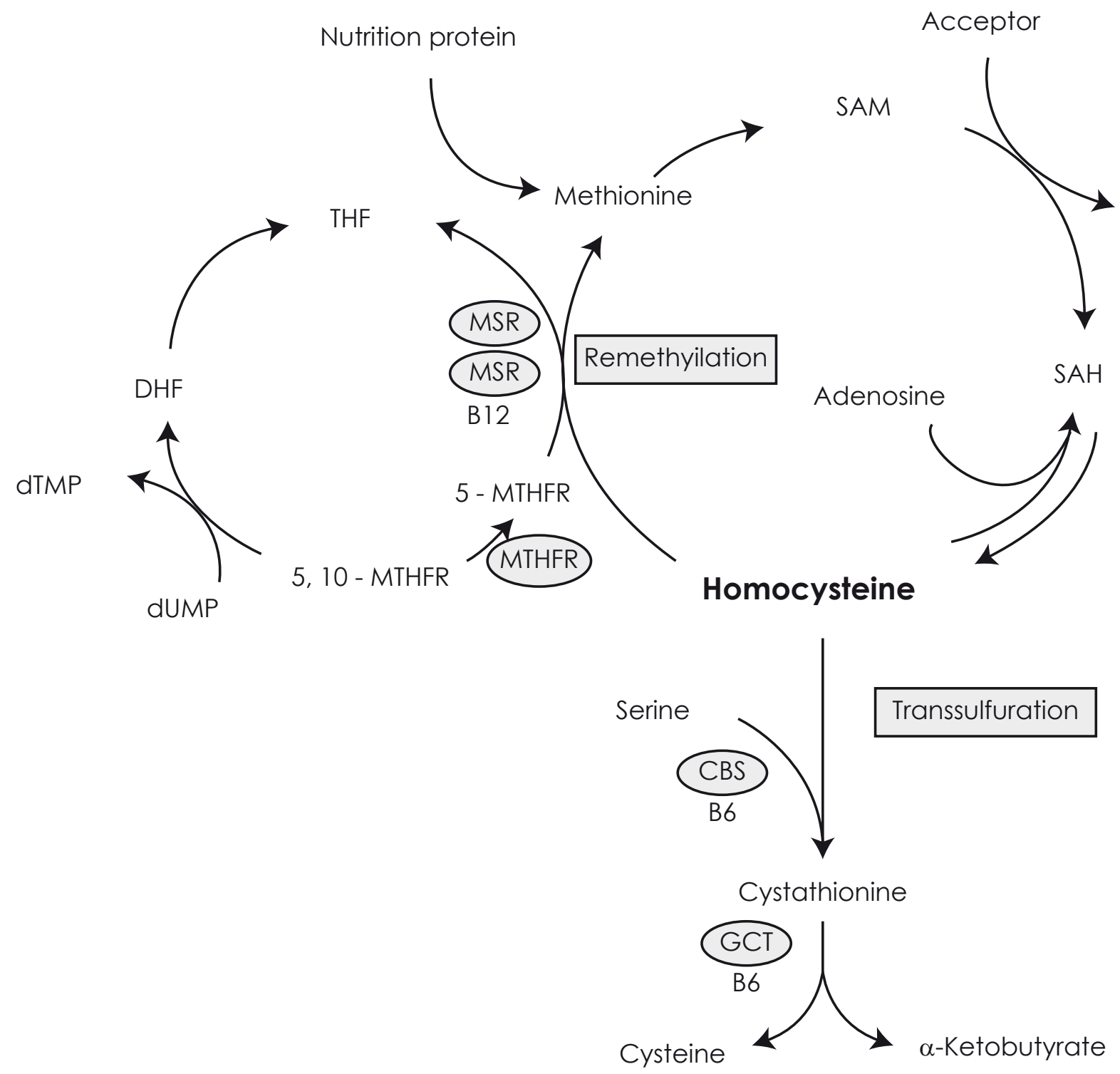

FIGURE 2. Metaboliolism of homocysteine. dUMP - desoxyuridine monophosphate, dTMP - desoxytimidine monophosphste, THF - tetrahydrofolate, DHF - dihydrofolate, 5-MTHF - 5-methyltetrahydrofolate, 5,10-MTHF - 5,10-methyltetrahydrofolate, 5,10 MTHFR - 5,10- methyltetrahydrofolate reductase, MS - metionin synthase, MSR - metionin synthase reductase, B12 - vitamin B12, SAM - S-adenosylmethionine, SAH - S-adenosylhomocysteine, CBS - cystathionine $\beta$-synthase, GCT - $y$-cystathionase, B6 - vitamin B6.

tions. ${ }^{20}$ Moreover, it seems that this mutation and the reduced activity of the enzyme MTHFR are not connected with hyperhomocysteinemia if persons have balanced diet with optimal intake of vitamins (B6, B12 and folates). ${ }^{19}$

Hyperhomocysteinemia is frequently associated with folate deficiency and it has been long postulated that the plasma homocysteine concentration is inversely related to the occurrence of cardiovascular disease and venous thrombosis. ${ }^{21-24}$

\section{Disturbed homocysteine metabolism, hyperhomo- cysteinemia and cancer}

Hyperhomocysteinemia is commonly occurring in a wide range of unrelated diseases. For example, in patients with renal failure a strong, positive correlation was observed between homocysteine (tHcy) levels, serum creatinine, and the renal 
glomerular filtration rate. Rheumatoid arthritis impaired gastric and other disturbances results often in elevated blood tHcy. ${ }^{25}$ The disease among which elevated tHcy are observed are: Systemic lupus erythematosus, non-insulin-dependent and insulin-dependent diabetes mellitus, hypothyroidism, cognitive impairment and neuropsychiatric disorders (dementia, depression, schizophrenia), fibromyalgia and chronic fatigue syndrome, Parkinson's disease, cerebrovascular disorders, and aseptic meningitis. ${ }^{26}$

Increased tHcy levels are often found in patients with neoplastic diseases. ${ }^{27}$ In vitro it was shown that some cancer cell lines are incapable of remethylating tHcy and it was recently shown that ovarian cancer cells from patients with elevated tHcy have impaired capacity to remethylate tHcy. ${ }^{28,29}$ Tempting to conclude that hyperhomocysteinemia in cancer patients could be secondary to the cancer. However, impaired methylation of DNA and polyamines has often been proposed to be involved in carcinogenesis ${ }^{30}$, so the combination of increased tHcy levels and impaired methylation capacity in patients has been proposed as being carcinogenic. ${ }^{31}$ In lymphocytes, positive correlation between cellular tHcy levels and increased chromosome damage was shown. ${ }^{31}$

Patient with malignancies often have an increased risk of venous thromboembolic (VTE) disease $^{5}$ and as such being the second most common cause of death in cancer patients, second to the primary disease itself. The pathophysiology of this association has not been precisely defined. However, it has been reported that in cancer patients several pro-coagulant factors are increased..$^{32}$ Other established contributors to the VTE increased risk is oncological therapy as chemotherapy, hormonal adjuvant therapy, surgery, central venous catheters, immobility and inherited thrombophilia. 5,33,34 However, this oncological therapy can also influence the immunological response of treatment patients..$^{35}$ In women with advanced breast cancer hyperhomocysteinemia is common. ${ }^{36}$ This observation could explain the high rate of venous thrombosis in women with metastatic breast malignancy. ${ }^{6}$ Furthermore, the association between MTHFR C677T polymorfism and breast cancer has been reported. However a positive correlation has not been confirmed by all studies. ${ }^{37}$ MTHFR C677T polymorphism is associated with changes in intracellular folate cofactors, affecting DNA methylation and synthesis via altered one-carbon transfer reactions. Of further notice on this association are potential ethnic differences. ${ }^{38}$
Al-Awadi et al. ${ }^{39}$ demonstrated with nude mice implanting human breast, prostate and pancreas tumour cells leads to decreased plasma cysteine, homocysteine and methionine levels over a twomonth period, which was a direct result from the progressing implanted tumour cells. In the case of methionine, the decrease was significant only due to progression of the breast tumours over a long time period. The results suggest that the sulphur amino acids cysteine, homocysteine and methionine can be potentially used as plasma or serum biomarkers for cancer progression.

Many other studies showed that the raised tHcy is related to the cancer itself and to the extent of the disease. ${ }^{21,40}$ After remission of the cancer in children with acute lymphoblastic leukemia the tHcy levels returned to normal. ${ }^{2}$

Both plasma concentration of homocysteine and neopterin, a catabolic product of guanosine triphosphate-GTP and as such an immune system activation marker, are closely associated and elevated in patients with various types of disease. ${ }^{3}$ From in vitro studies it has been shown that tumour cells and other proliferating cells release homocysteine. ${ }^{41}$ This in vitro notion might be extrapolated to the in vivo situation and could explain why hyperhomocysteinemia is observed in patients with various kinds of cancers. Within cellular immune activation, $\mathrm{T}$ cells release large amounts of the cytokine IFN- $\gamma$, which stimulates human monocyte-derived macrophages and dendritic cells to produce neopterin. ${ }^{42}$ For example, in cancer patients, increased urine and plasma neopterin concentrations have been reported, suggesting enhanced cellular immune activation. ${ }^{43,44}$ Therefore, immune activation cascades might also be an important triggers for the accumulation of plasma homocysteine in various diseases, including malignancies.

When different tumours are compared, the frequency of increased neopterin concentration is much lower in patients with breast cancer that it is in patients with other types of cancers. ${ }^{3}$ Although no association between neopterin and tumour size or lymph node status has been shown in women with breast cancer, follow-up examinations reveal that at diagnosis high urine neopterin concentrations are associated with shorter survival. ${ }^{4}$ However, these authors conclude that plasma homocysteine and neopterin concentrations are only rarely elevated in breast cancer patients and they note that the activation and proliferation of immunocompetent cells rather than tumour cells proliferation is responsible for hyperhomocysteinemia in these breast cancer patients. 


\section{B vitamins for cancer prevention}

Folate, vitamin B12, and vitamin B6, have a number of biologic roles that make them potentially important in cancer. Within DNA synthesis they function as coenzymes in the synthesis of purines and thymidylate. Diminished levels of these vitamins may result in misincorporation of uracil into DNA, leading to chromosome breaks and disruption of DNA repair. ${ }^{45}$ As explained earlier both folate and vitamin B12 are involved in DNA methylation. Deficient folate and vitamin B12 levels can reduce the availability of S-adenosylmethionine, the universal methyl donor, for DNA methylation and may thereby influence gene expression.

Inadequate body levels of biologically active folate, vitamin B6, and vitamin B12 are primary determinants of high blood homocysteine levels. ${ }^{46}$ Folic acid is a component of food which has been associated with lower cancer risk in epidemiologic studies. ${ }^{910,47,48}$ Wide geographical variation and migrant studies in cancer incidence and mortality suggest that diet and other lifestyle factors as physical activity influence cancer risk. ${ }^{49,50}$ Data on cancer incidence and mortality are available from 37 countries and analysis showed that incidence of colorectal cancer was inversely correlated with more cereals (grains) in the diet. ${ }^{51}$ Folic acid present in a wide variety of plant foods, such the legumes, vegetables, fruits and whole grains is thought to be protective against colorectal cancer..$^{52,53}$ The lack of folic acid in animal cells studies resulted in DNA defects that resemble effects found in cancer cells.

It has been hypothesized in many epidemiologic studies $^{38,54,55}$ that cancer can be initiated by DNA damage (increasing DNA methylation, and by repairing and reducing formation of DNA strand breaks of p53 and Apc genes) caused by folic acid deficiency. ${ }^{56,57}$ A deficiency of folic acid leads to a low level of thymidilic acid and alterations in the pool of nucleotides available for DNA and RNA synthesis. It is even suggested that adequate folate intake may be important in the prevention of breast cancer, particularly among women who consume alcohol. ${ }^{58-60}$ Alcohol is a known folate antagonist and thus could increase an individual's requirement for folate intake. For vitamin B12, unlike folate, variation in amount absorbed rather than intake is the main determinant of plasma levels in Western populations. ${ }^{61}$ In a prospective study analysis of collected blood from 195 case-control pairs, low plasma levels of vitamin B12 were associated with increased risk of breast cancer among postmenopausal women; however, low plasma levels of folate, and homocysteine were not associated with breast cancer risk. ${ }^{62}$ Hypofolatemia and metabolic alteration in homocysteine, vitamin B12 could be associated with laryngeal cancer. ${ }^{63}$ Therefore, a great effort was made to proof this association as it was made to find association between cysteine cathepsins as well as stefins and promoting and invasion of head and neck tumours. ${ }^{63,64}$ Increased plasma vitamin B12 concentration may reduce the risk of rectal cancer. ${ }^{65}$

A recent animal study demonstrated that a B12deficient diet, which was of insufficient severity to cause anemia or illness, disturbed normal homeostasis of one-carbon metabolism in the colonic mucosa and resulted in diminished genomic DNA methylation and increased uracil misincorporation in DNA, both of which are purported mechanisms for onecarbon metabolism-related colonic carcinogenesis ${ }^{66}$

In a large prospective study on health care professionals, high intake of folic acid was found to be significantly correlated with low incidence of colorectal adenomas (polyps) ${ }^{67}$ Therefore the diet regime and life style factors should be consider as primary prevention beside also important secondary prevention. ${ }^{49,50,68}$ Case control studies have as well as found high folic acid intake to be correlated with low risk for either pancreatic cancer or breast cancer. ${ }^{69,70}$ In Greece and in Argentina studies correlating breast cancer and diet found risk reductions from six to ten fold in subjects eating mostly vegetables rich of $\mathrm{B}$ vitamins. ${ }^{71}$ The high risk of developing cancer in a lifetime in the North American and Western European societies might be related to the low intake of vegetables and particularly folic acid might be lacking in diets. Folic acid deficiency could be the permissive condition that enables DNA damage to occur and accumulate. This can lead to DNA damage and cancer.

\section{Is synthetic folate fortification always good for us?}

Many countries have implemented mandatory folic acid fortification of flour and grain products to reduce the risk of various diseases, especially neuraltube birth effects. Experimental evidence suggests that high doses of folic acid may enhance growth of cancer cells.7,53,72,73 These effects have resulted in substantial increase in circulating folate and unmetabolized folic acid concentration. ${ }^{72,74}$ Described 
the beneficial effects of folate in preventing cancer, it is also well known that high intake of synthetic folic acid might mask vitamin B12 deficiency. ${ }^{74}$ Experimental studies suggest that excessing folic acid may promote the progression of already existing preneoplasms. ${ }^{7}$ Responsible mechanisms of high folates concentration causing cancer promoting effects include folates providing nucleotide precursors for the preneoplastic cells improving their replication and proliferation. Folates, methyl donors might lead to a de novo methylation and subsequent inactivation of tumour-suppressor genes, resulting in accelerated tumour progression. ${ }^{7}$ The safe upper limit for folate intake as well as the safe upper folate concentration in blood are not known. ${ }^{6}$ The mandatory fortification of food with folic acid, it dose and the time of intervention depends by the country's decision. ${ }^{72}$

Because the safety of folate might depend on its chemical structure (natural folate or synthetic folic acid), there is the question of potential adverse effects of circulating unmetabolized folic acid. ${ }^{75}$

\section{Conclusions}

Many data support a relationship between hyperhomocysteinemia, low B vitamins concentration and risk for various types of cancer. Defective metabolism of tHcy in carcinogenesis is well documented, but the pathophysiology of this association is not fully understood. Many authors suggest that factors contributing to folate status are not protective against certain type of cancer, so further studies are needed to explore folate studies in human.

\section{Acknowledgement}

The authors thank Dr. Cècil J.W.Meulenberg and MSc. Majda Šavle from College of Health Care, University of Primorska, Slovenia, for manuscript reading and their useful comments.

\section{References}

1. Fassbender K, Orell M, Hennerici M. Plasma Homocyst(e)ine Concentrations in Cerebrovascular Disease. Stroke 1999; 30: 2224-38.

2. Sun CF, Haven TR, Wu TL, Tsao KC, Wu JT. Serum total homocysteine increases with the rapid proliferation rate of tumor cells and decline upon cell death: a potential new tumor marker. Clin Chim Acta 2002; 321: 55-62.

3. Trosseau A. Phlegmasia alba dolens. Clin de l'Hotel-Dieu de Paris 1865; 3: 654-712.

4. Debevec $L$, Jerič $T$, Kovač $V$, Sok $M$, Bitenc $M$. The progress in routine management of lung cancer patients. A comparative analysis of an institution in 1996 and 2006. Radiol Oncol 2009; 43: 47-53.
5. Rickles FR, Levine M, Edwards RL. Hemostatic alteration in cancer patients. Cancer Metastasis Rev 1992; 11: 237-48.

6. Smith $\mathrm{AD}, \mathrm{Kim} \mathrm{Yl}$, Refsum $\mathrm{H}$. Is folic acid good for everyone? Am J Clin Nut 2008; 87: 517-33.

7. Kim YI. Folate: a magic bullet or a double edged sword for colorectal cancer prevention? Gut 2006; 55: 1387-89.

8. Cole BF, Baron JA, Sandler RS, Haile RW, Ahnen DJ, Bresalier RS et al. Folic acid for the prevention of colorectal adenomas: a randomized clinical trial. JAMA 2007; 297: 2351-59.

9. Hirsch S, Sanchez H, Albala C, de la Maza MP, Barrera G, Leiva L et al. Colon cancer in Chile before and after the start of the flour fortification program with folic acid. Eur J Gastroeneterol Hepatol 2009; 21: 436-39.

10. Mason JB, Dickstein A, Jacques PF, Haggarty P, Selhub J, Dallal G, et al. A temporal association between folic acid fortification and an increase in colorectal cancer rates may be iluminating important biological principles: a hypothesis. Cancer Epidemiol Biomarkers Prev 2007; 16: 1325-29.

11. Weisberg IS, Park E, Ballman KV, Berger P, Nunn M, Suh DS, et al. Investigations of a common genetic variant in betaine-homocysteine methyltransferase (BHMT) in coronary artery disease. Atherosclerosis 2003; 167: 205-14.

12. Voet D, Voet JG. Biochemistry (2nd ed.). New York: John Wiley and Sons, Inc; 1995.

13. Ridker PM, Manson JE, Buring JE, Shih J, Matias M, Hennekens CH Homocysteine and risk of cardiovascular disease among postmenopausal women. JAMA 1999; 281: 1817-21.

14. Stanger O, Herrmann W, Pietrzik K, Flower B, Geisel J, Dierkes J, et al. DACHLIGA Homocystein (German, Austrian and Swiss Homocysteine Society): Consensus paper on the regional clinical use of homocysteine, folic acid and B-vitamins in cardiovascular and thrombotic diseases: guidelines and recommendations. Clin Chem Lab Med 2003; 41: 1392-403.

15. de Bree A, van Dusseldorp M, Brouwer IA, Van het Hof KH, SteegersTheunissen RPM. Folate intake in Europe: recommended, actual and desired intake. Eur J Clin Nutr 1997; 51: 643-60.

16. Herrmann W. The Importance of Hyperhomocysteinemia as a Risk Factor for Diseases: An Overview. Clin Chem Lab Med 2001; 39: 666-74.

17. Kachanov DY, Dobrenkov KV, Shamanskaya TV, Abdullaev RT, Inushkina EV, Savkova RF, et al. Solid tumors in young children in moscow Region of Russian Federation. Radiol Oncol 2008; 42: 39-44.

18. Fodinger M, Horl WH, Sunder-Plassmann G. Molecular biology of 5,10-methylenetetrahydrofolate reductase. J Nephrol 2000; 13: 20-33.

19. Silaste ML, Rantala M, Sämpi M, Alfthan G, Ato A, Kasänieiemi A Polimorphisms of key enzymes in homocysteine metabolism affect diet responsiveness of plasma homocysteine in healthy women. J Nutr 2001; 131: 2643-47.

20. Schriver RC, Beaudet AL, Sly WS, Valle D eds. The metabolic and molecula basis of inherited disease. New York: Mc-Graw-Hill; 1995. p: 1276-1319.

21. Heijer den M, Rosendaal FR, Blom HJ, Gerrits WBJ, Bös GMJ. Hyperhomocysteinemia and Venous Thrombosis: A Meta - analysis. Thromb Haemost 1998; 80: 874-7.

22. Biasioli S, Schiavon R. Homocysteine as a cardiovascular risk factor. Blood Purif 2000; 18: 177-82

23. Ridker PM, Hennekens $\mathrm{CH}$, Selhub J, Mletich JP, MalinoW MR, Tampfer J. Interrelation of hyperhomocysteinemia, factor $\mathrm{V}$ Leiden, and risk of venous thromboembolism. Circulation 1997; 95: 177-82.

24. Clarke R, Levington S, Donald A, Johnston C, Refsum H, Stratton I, et al Underestimation of the importance of homocysteine as a risk factor for cardiovascular disease in epidemiological studies. J Cardiovasc Risc 2001; 8: 396-9.

25. Hultberg B, Andersson A, Sterner G. Plasma homocysteine in renal failure. Clin Nephrol 1993; 40: 223-35.

26. Pettersson T, Friman C, Abrahamsson L, Nilsson B, Norberg B. Serum homocysteine and methylmalonic acid in patients with rheumatoid arthritis and cobalaminopenia. J Rheumatol 1998; 25: 859-63.

27. Bolander-Gouaille C. Focus on Homocysteine. Clinical conditions associated with hyperhomocysteinemia. New York: Springer-Verlag France, Heidelberg; 2001. p. $47-68$ 
28. Fiskerstrand T, Ueland PM, Refsum H. Response of the methionine synthase system to short-term culture with homocysteine and nitrous oxide and its relation to methionine dependence. Int J Cancer 1997; 72: 301-6.

29. Corona G, Toffoli G, Fabris M, Viel A, Zarrelli A, Donada C, et al. Homocysteine accumulation in human ovarian carcinoma ascitic/cystic fluids possibly caused by metabolic alteration of the methionine cycle in ovarian carcinoma cells. Eur J Cancer 1997; 33: 1284-90.

30. Poirier LA. Methyl group deficiency in hepatocarcinogenesis. Drug Metab Rev 1994; 26: 185-99.

31. Fenech MF, Dreosti IE, Rinaldi JR. Folate, vitamin B12, homocysteine status and chromosome damage rate in lymphocytes of older men. Carcinogenesis 1997; 18: 1329-36.

32. Falanga A, Barbui T, Rickles FR, Levine MN. Guidelines for clotting studies in cancer patients. For the Scientific and Standardization Committee of the Subcommittee on Haemostasis and Malignancy International Society of Thrombosis and Haemostasis. Thromb Haemost 1993; 70: 540- 42.

33. Prandoni P. Venous thromboembolism risk and management in women with cancer and thrombophilia. Gen Med 2005; 2: S28-S34.

34. Kessler CM. The Link Between Cancer and Venous Thromboembolism: Review. Am J Clin Oncol 2009; 32(4 Suppl): S3-S7.

35. Dovsak T, Ihan A, Didanovic V, Kansky A, Hren Ihan NI. Influence of surgica treatment and radiotherapy of the advanced intraoral cancers on complete blood count, body mass index, liver enzymes and leukocyte CD64 expression. Radiol Oncol 2009; 43: 282-92.

36. Gatt A, Makris A, Cladd $\mathrm{H}$, Burcombe $\mathrm{RJ}$, Smith $\mathrm{JM}$, Cooper $\mathrm{P}$, et al. Hyperhomocysteinemia in women with advanced breast cancer. Int J Lab Hem 2007; 29: 421-5.

37. Hekim N, Ergen A, Yaylim I, Yilmaz H, Zeybek U, Oztürk O, et al. No association between methylenetetrahydrofolate reductase C677T polymorphism and breast cancer. Cell Biochem Funct 2007; 25: 115-7.

38. Jennings E. Folic acid as a cancer- preventing agent. Medical Hypotheses 1995; 45: 297-303.

39. Al-Awadi F, Yang M, Tan Y, Han Q, Li S, Hoffman RM. Human tumor growth in nude mice is associated with decreased plasma cysteine and homocysteine. Anticancer Res 2008; 28: 2541-4.

40. Kishi S, Griener J, Cheng C, Das S, Cook EH, Pei D, et al. Homocysteine, pharmacogenetics, and neurotoxicity in children with leukemia. J Clin Oncol 2003; 21: 3084-91.

41. Wu LL, Wu JT. Hyperhomocysteinemia is a risk factor for cancer and a new potential tumor marker. Clin Chim Acta 2002; 322: 21-8.

42. Wirleitner B, Reider D, Ebner S, Böck G, Widner B, Jaeger M, et al. Monocyte-derived dendritic cells release neopterin. J Leukoc Biol 2002; 72: 1148-53.

43. Murr C, Bergant A, Widschwendter M, Heim K, Schröcksnadel H, Fuchs D. Neopterin is an independent prognostic variable in females with breast cancer. Clin Chem 1999; 45: 1998-2004.

44. Murr C, Fuith LC, Widner B, Wirleitner B, Baier-Bitterlich G, Fuchs D. Increased neopterin concentrations in patients with cancer: indicator of oxidative stress? Anticancer Res 1999; 19(3A): 1721-8.

45. Blount BC, Mack MM, Wehr CM, MacGregor JT, Hiatt RA, Wang G, et al. Folate deficiency causes uracil misincorporation into human DNA and chromosome breakage: implications for cancer and neuronal damage. Proc Natl Acad Sci USA 1997; 94: 3290-5.

46. Selhub J, Jacques PF, Wilson PW, Rush D, Rosenberg IH. Vitamin status and intake as primary determinants of homocysteinemia in an elderly population. JAMA 1993; 270: 2693-8.

47. Freudenheim JL, Graham S, Marshall JR, Haughey BP, Cholewinski S, Wilkinson G. Folate intake and carcinogenesis of the colon and rectum. Int J Epidemiol 1991; 20: 368-74.

48. Benito E, Stiggelbout A, Bosch FX, Obrador A, Kaldor J, Mulet M, et al. Nutritional factors in colorectal cancer risk: a case-control study in Majorca. Int J Cancer 1991; 49: 161-67.

49. Martinez MA. Diet and cancer prevention: the roles of observation and experimentation. Nat Rev Cancer 2008; 8: 694-703.

50. Perše M, Cerar A. [Physical activity and colorectal cancer]. [Slovenian]. Zdrav Vestn 2009; 78: 399-405.
51. Armstrong B, Doll R. Environmental factors and cancer incidence and mortality in different countries, with special reference to dietary practices. Int $J$ Cancer 1975; 15: 617-31.

52. Jennings E. Apricots and oncogenes: on vegetables and cancer prevention. Cleveland, Ohio: McGuire \& Beckley; 1993.

53. Akoglu B, Milovic V, Caspary WF and Faust D. Hyperproliferation of homocysteine-tretaed colon cancer cells is reversed by folate and 5-methyltetrahydrofolate. Eur J Nutr 2004; 43: 93-9.

54. James SJ, Cross DR, Miller BJ. Alterations in nucleotide pools in rats fed diets deficient in choline, methionine and/or folic acid. Carcinogenesis 1992; 13: 2471-74.

55. Kunz BA. Mutagenesis and deoxyribonucleotide pool imbalance. Mutat Res 1988; 200: 133-47.

56. Duthie SJ, Narayanan S, Brand GM, Pirie L, Grant G. Impact of folate deficiency on DNA stability. J Nutr 2002; 132(8 Suppl): 2444S-9S.

57. Kim YI, Shirwadkar S, Choi SW, Puchyr M, Wang Y, Mason JB. Effects of dietary folate on DNA strand breaks within mutation-prone exons of the p53 gene in rat colon. Gastroenterol 2000; 119: 151-61.

58. Zhang S, Hunter DJ, Hankinson SE, Giovannucci EL, Rosner BA, Colditz GA, et al. A prospective study of folate intake and the risk of breast cancer. JAMA 1999; 281: 1632-7.

59. Rohan TE, Jain MG, Howe GR, Miller AB. Dietary folate consumption and breast cancer risk. J Natl Cancer Inst 2000; 92: 266-9.

60. Sellers TA, Kushi LH, Cerhan JR, Vierkant RA, Gapstur SM, Vachon CM, et al. Dietary folate intake, alcohol, and risk of breast cancer in a prospective study of postmenopausal women. Epidemiology 2001; 12: 420-8.

61. Willett WC. Nutritional epidemiology. New York: Oxford University Press; 1998.

62. Potischman N, Swanson CA, Coates RJ, Gammon MD, Brogan DR, Curtin J, et al. Intake of food groups and associated micronutrients in relation to risk of early-stage breast cancer. Int J Cancer 1999; 82: 315-21.

63. Nacci A, Dallan I, Bruschini L, Traino AC, Panicucci E, Bruschini P, et al. Plasma homocysteine, folate, and vitamin B12 levels in patients with laryngeal cancer. Arch Otolaryngol Head Neck Surg 2008; 134: 1328-33.

64. Strojan P. Cysteine cathepsins and stefins in head and neck cancer: an update of clinical studies. Radiol Oncol 2008; 42: 69-81.

65. Dahlin AM, Van Guelpen B, Hultdin J, Johansson I, Hallmans G, Palmqvist R. Plasma vitamin B12 concentrations and the risk of colorectal cancer: a nested case-referent study. Int J Cancer 2008; 122: 2057-61.

66. Friso S, Sang Woon C. The potential cocarcinogenic effect of vitamin B12. Clin Chem Lab Med 2005; 43: 1158-63.

67. Giovannucci E, Stampfer MJ, Colditz GA, Rimm EB, Trichopoulos D, Rosner $\mathrm{BA}$, et al. Folate, methionine, and alcohol intake and risk of colorectal adenoma. J Natl Cancer Inst 1993; 85: 875-84.

68. Sofic A, Sehovic N, Beslic S, Prnjavorac B, Bilalovic N, Caluk J, et al. $M R$ rectum imaging with ultra sound gel as instrumental contrast media in tubulovillous adenoma. Radiol Oncol 2008; 42: 136-42.

69. Baghurst PA, McMichael AJ, Slavotinek AH, Baghurst KI, Boyle P, Walker AM A case-control study of diet and cancer of the pancreas. Am J Epidemio 1991; 134: 167-79.

70. Graham S, Hellmann R, Marshall J, Freudenheim J, Vena J, Swanson M, et al Nutritional epidemiology of postmenopausal breast cancer in western New York. Am J Epidemiol 1991; 134: 552-66.

71. Iscovich JM, Iscovich RB, Howe G, Shiboski S, Kaldor JM. A case-control study of diet and breast cancer in Argentina. Int J Cancer 1989; 44: 770-6.

72. Osterhues A, Holzgreve W, Michels KB. Shall we put the world on folate? Lancet 2009; 19: 959-61.

73. Ulrich CM, Potter JD. Folate and cancer: timing is everything. JAMA 2007 297: 2408-9.

74. Shane B. Folate fortification: enough already? Am J Clin Nutr 2003; 77: 8-9.

75. Kalmbach RD, Choumenkovitch SF, Troen AM, D'Agostino R, Jacques PF, Selhub J. Circulating folic acid in plasma: relation to folic acid fortification. Am J Clin Nutr 2008; 88: 763-8. 